\title{
A FAMÍLIA LGBTI NA PERSPECTIVA DO DIREITO INTERNACIONAL DOS REFUGIADOS
}

\section{THE LGBT FAMILY IN THE PERSPECTIVE OF INTERNATIONAL REFUGEES LAW}

\author{
Patricia Cristina Vasques de Souza Gorisch ${ }^{1}$
}

Recebido em: 04/11/ 2016 Aceito em: 19/12/2016

patricia@patriciagorisch.adv.br

Resumo: O presente estudo visa fazer uma reflexão acerca das famílias $L_{G B T I}{ }^{23}$ na perspectiva do direito internacional dos refugiados na atual situação. Muitos ${ }^{4}$ LGBTI fogem de seus países de origem em busca de segurança para viver. Há ainda a criminalização pela orientação sexual e identidade de gênero em pelo menos 75 países $^{5}$, o que justifica a fuga em busca de refúgio. O Alto Comissariado das Nações Unidas para os Refugiados - ACNUR, reconhece a condição de refugiado LGBTI, ou seja, aquelas pessoas do grupo social LGBTI que fogem de seus países de origem pela perseguição da condição SOGI ${ }^{6}$. No estudo, verificaremos que a União Europeia editou uma lista de "países seguros" aos refugiados, que diante da crise humanitária iniciada em 2014, causou o maior deslocamento de pessoas desde a $2^{\mathrm{a}}$. Guerra Mundial. Ocorre que tais países "seguros" não são seguros aos refugiados LGBTI. Ademais, verificaremos que um dos princípios basilares do refúgio é o da reunião familiar, ou seja, se um refugiado LGBTI está no país sob esta condição, tem o direito de ter sua família ao seu lado, que também receberá a proteção e a condição de refugiado. Ocorre que os refugiados LGBTI fogem de seus países justamente porque lá eles não são reconhecidos como casal, não tem direitos, sofrem perseguição e violências severas. Quando chegam na Europa, por não terem certidão de casamento, são separados de seus amores.

Palavras-chave: LGBTI. Refugiados. Reunião familiar.

Abstract: This study aims to reflect about the LGBTI families in view of international refugee law in the current situation. Many LGBTI fleeing their home countries in search of safety to live. There is also the criminalization of sexual orientation and gender identity in at least 75 countries, which justifies the flight for refuge. The UN High Commissioner for Refugees UNHCR recognized refugee status LGBTI, ie those people LGBTI social group fleeing their countries of origin by persecution of SOGI condition. In the study, we find that the European Union issued a list of "safe countries" to refugees, which started on the humanitarian crisis in 2014 caused the largest displacement of people since the 2 nd. World War. It happens that such "safe" countries are not safe to LGBTI refugees. Moreover, we find that one of the basic refuge principles is the family reunion, or a LGBTI refugee is in the country under this condition has the right to have his family at his side, which will also receive the protection and condition refugee. It happens that the LGBTI refugees fleeing their countries precisely because there they are not recognized as a couple, have no rights, are persecuted and severe violence. When they arrive in Europe, for failing marriage certificate, they are separated from their loves.

Keywords: LGBTI. Refugees. Family reunion.

\footnotetext{
${ }^{1}$ Universidade Católica de Santos - UNISANTOS - Santos - São Paulo - Brasil

${ }^{2}$ Sigla para lésbicas, gays, bissexuais, transgêneros e intersexos.

${ }^{3}$ Lésbica é a mulher que de forma física, romântica e /ou emocional se atraia por outra mulher. • Gay é usualmente usado para descrever o homem mulher que de forma física, romântica e /ou emocional se atraia por outro homem, apesar do termo ser usado também para lésbicas • Bisexual é o indivíduo que que de forma física, romântica e /ou emocional se atraia por outra mulher e homem. • Transgênero é a pessoa cuja identidade ou expressão de gênero difere do sexo que foram designados no nascimento. $\bullet O$ termo intersexo cobre as variações do corpo de acordo com os standards de masculino e feminine, incluindo variações de níveis de cromossosmos, gônadas e genitais.

${ }^{4}$ Cerca de 1070 em 2014 na Bélgica. http://ilgaeurope.org/sites/default/files/Attachments/ilga_europe_briefing_on_lgbti_asylum_issues_february_2016.pdf acesso em 15/05/2016.

${ }^{5}$ Idem.

${ }^{6}$ Sexual orientation and gender identity
} 


\section{INTRODUÇÃO}

As pessoas LGBTI que, em razão de sua condição de orientação sexual ou identidade de gênero (SOGI, na sigla em inglês), que buscam refúgio, são particularmente mais vulneráveis que os refugiados motivados por outras formas de perseguição, como as de opinião política, raça, religião ou nacionalidade?

Aqueles que fogem pelo motivo da orientação sexual ou identidade de gênero, sofrem inúmeras situações graves, como discriminação, violência física, sexual e psicológica, abuso sexual, falta de proteção policial, exclusão aos serviços básicos de saúde, educação, detenção abusiva, estupros corretivos, exclusão social e familiar. O fato de serem e de amarem pessoas que não pertençam à heteronormatividade, torna a vida em seus países de origem insuportável e perigosa.

Em busca de novas perspectivas, fogem de seus países de origem em busca de refúgio. Desde $2011^{8}$ o Conselho de Direitos Humanos da ONU reconhece os direitos LGBTI como direitos humanos e além disto, o ACNUR (Alto Comissariado das Nações Unidas para o Refugiado) reconhece a condição de orientação sexual e/ou identidade de gênero dos LGBTI como causa de pedir o refúgio no motivo de pertencimento a certo grupo social ${ }^{9}$.

Com este reconhecimento, muitos LGBTI que tentavam refúgio (às vezes sem sucesso) pelo motivo SOGI, agora conseguem a proteção internacional. Porém, a solução ainda está longe de ocorrer. De acordo com o próprio ACNUR, o Brasil tem um grande potencial de recebimento de refugiados. De acordo com o CONARE ${ }^{10}$, o Brasil possui atualmente (abril de 2016) 8.863 refugiados reconhecidos, de 79 nacionalidades distintas (28,2\% deles são mulheres) - incluindo refugiados reassentados. Os principais grupos são compostos por nacionais da Síria (2.298), Angola (1.420), Colômbia (1.100), República Democrática do Congo (968) e Palestina (376). Muitos chegam de países que criminalizam a SOGI, com penas que vão de prisão perpétua até pena de morte. Muitos ao chegar aqui, não falam o real motivo do refúgio, pois não conhecem as condições brasileiras no tocante a discriminação por orientação sexual ou identidade de gênero.

A guerra na Síria já provocou quase 5 milhões de refugiados e é a pior crise humanitária desde a $2^{\mathrm{a}}$. Guerra Mundial. Com o avanço da ISIS/Estado Islâmico, o ódio aos LGBTI aumentou, causando pânico a esta população que foge em busca de refúgio. O COI (análise de pesquisa do país de origem) é peça chave para que tais pessoas sejam amparadas pelo direito internacional e nacional, pois analisando o país de origem, dará o subsídio correto e pontual do tomador de decisão ou do entrevistador que fará o relatório e enviará ao CONARE, órgão no Brasil que decide pela concessão ou não de refúgio.

\footnotetext{
${ }^{7}$ De acordo com a Convenção de 1951 da ONU e o Protocolo de 1967, referente aos refugiados.

${ }^{8}$ A/HRC/17/L.9 General Assembly of UN, Human Rights Council. 17th session, Follow-up and implementation of the Vienna Declaration. http://pt.scribd.com/doc/58106434/UN-Resolution-on-Sexual-Orientation-andGender-Identity. Último acesso em 24.07.2011.

${ }^{9}$ http://www.unhcr.org/news/latest/2015/12/567bb2869/unhcr-leads-in-lgbti-refugee-asylum-seekerprotection.html acesso em 15/05/2016

${ }^{10}$ http://www.acnur.org/t3/portugues/recursos/estatisticas/dados-sobre-refugio-no-brasil/ acesso em $15 / 05 / 2016$
}

Revista do Direito [ISSN 1982-9957]. Santa Cruz do Sul, v. 3, n. 50, p. 71-80, set./dez. 2016. https://online.unisc.br/seer/index.php/direito/index 
Em setembro de 2013, o CONARE publicou a Resolução $n^{\circ} .17$ que autorizou as missões diplomáticas brasileiras a emitir visto especial a pessoas afetadas pelo conflito na Síria, diante do quadro de graves violações de direitos humanos. Em 21 de setembro de 2015, a Resolução teve sua duração prorrogada por mais dois anos. Os critérios de concessão do visto humanitário atendem à lógica de proteção por razões humanitárias, ao levar em consideração as dificuldades específicas vividas em zonas de conflito, mantendo-se os procedimentos de análise de situações vedadas para concessão de refúgio. Note-se que a vulnerabilidade das pessoas LGBTI é tamanha que não basta a lei deixar de proibir as relações homoafetivas; a sociedade tem que aceitar, para justamente essas pessoas não sofrerem violência.

Uma questão essencial ainda deve ser levada em consideração: pessoas LGBTI que fugiram de seus países de origem pelo motivo de LGBTIfobia, nem sempre alegam o seu real motivo quando chegam no país onde irá solicitar o seu refúgio. Para este grupo vulnerável, há que se entender que muitos chegam no país sem saber se aquele país efetivamente aceita pessoas LGBTI. E mais, se os aceita, há ainda casos de recepção, como na Inglaterra e Canadá ${ }^{11}$, em que oficiais de fronteira praticam violência psicológica e estupros corretivos, ou ainda países como a Alemanha, que praticam o teste de falometria ${ }^{12}$.

Com base na pesquisa realizada, a orientação sexual ou identidade de gênero é vista como causa de solicitação de refúgio. Em recente manual lançado ${ }^{13}$ pela ONU, há o reconhecimento de violência e perseguição endêmica aos LGBTI e que ainda não há um profundo estudo nas questões de asilo, solicitação de refúgio e migração de LGBTI's no mundo.

Até chegarem ao Brasil, percorrem um grande caminho.Os refugiados sírios LGBTI, que atualmente além de fugirem do governo sangrento de Assad, fogem do Estado Islâmico percorrendo o caminho até a Turquia ou Grécia. De lá, são direcionados a centros de refugiados que ao saberem do motivo do refúgio pelos oficiais de fronteira, são levados a responder questões insensíveis ou inapropriadas; sofrem intolerância, violência, discriminação, diferenciação no tratamento com a saúde, acesso a alimentos e emprego, além de se sujeitar a práticas sexuais ditas corretivas (estupros).

A maioria das leis que criminaliza a atividade sexual entre pessoas do mesmo sexo localizamse em países da África, Ásia (Pacífico) e Meio Oeste e Norte da África. No Direito Internacional, o documento central para determinação da condição de refugiado, a Convenção Relativa ao Estatuto dos Refugiados de 1951, reconhece o princípio da unidade familiar como direito essencial para o refugiado. Segundo o Estatuto, o direito de refúgio deve ser estendido para os membros de sua família.

Na prática a reunificação familiar concede o refúgio aos membros de um refugiado, podendo estes serem filhos ou cônjuges e em alguns casos único parente vivo ou vulnerável. Quando discutido

\footnotetext{
${ }^{11}$ Deloitte, 2011. Report on willingness of reporting incidents related to religion and sexual orientation in reception facilities, 20/12/2011.

${ }^{12}$ Exame realizado no solicitante de refúgio com base no SOGI, onde mede-se o grau de excitação sexual em filmes de sexo explícito homossexual para provar a veracidade do motivo de refúgio.

${ }^{13}$ UNHCR. TRAINING OVERVIEW GUIDE FOR FACILITATORS: working with LGBTI persons. Setembro, 2015.
} 
dentro da temática LGBTI, extensão do refúgio fundamentada pela reunificação recai nesse sentido sobre um tema onde a própria definição de família entra em debate, inclusive na sociedade Brasileira.

É notável que a definição de família, considerável para a extensão do refúgio fundamentada pela reunificação, recai nesse sentido sobre um tema que é palco de debate dentro do contexto LGBTI. No contexto Europeu, os artigos 9-12 da Diretiva de Reunião Familiar 2003/86/EC ${ }^{14}$ estabelecem que aqueles reconhecidos como refugiados têm direito a ter sua família reunida, permitindo a proteção subsidiária aos membros familiares assim como o membro primeiramente reconhecido como refugiado.

Porém, essa tese faz frente à uma realidade onde casais e famílias homoafetivas muitas vezes não têm reconhecimento legal em seus países de origem. Aquele que solicita o refúgio em função de sua Orientação Sexual e/ou Identidade de Gênero é geralmente oriundo de países que não só não reconhecem a união homoafetiva como ilegalizam e punem com a morte a sexualidade distinta. A ameaça de morte por ser LGBTI é uma realidade em 4 dos principais países de origem para refugiados no mundo (ILGA, 2015, p.29). A impossibilidade de reconhecimento da família perante a lei caracteriza discriminação, como indica o parágrafo 69 do Relatório da Agência da ONU para Refugiados (ACNUR) sobre práticas discriminatórias contra indivíduos LGBTIs, onde é colocado que onde não há reconhecimento oficial há possibilidade de discriminação por agentes privados, como agências de seguros e planos de saúde.

A Reunificação familiar, no contexto regional Europeu, deve ser conforme a Convenção Europeia de Direitos Humanos. $\mathrm{O}$ artigo $8 \mathrm{em}$ especial estabelece o direito do respeito à vida privada e à família. Nesse contexto, a Corte Europeia de Direitos Humanos em seus julgamentos busca balancear o princípio do controle dos Estados-membros sobre a imigração e o respeito aos Direitos Humanos (Sußner, 2013, p.183). Esse dilema é aqui elencado em alguns casos na forma da discussão da Reunificação Familiar, agravada pela questão LGBTI explorada de forma hipotética.

Nas diretivas da União Europeia, família é o membro nuclear - esposa/marido, crianças menores de idade e parentes desacompanhados de menores de idade. Esta definição de família é limitada e não considera os novos arranjos familiares vindos do drama da guerra civil, perseguição religiosa ou de etnia, nos casos de migração forçada, ignorando os casos da família extensa.

Casais e famílias homoafetivas muitas vezes não têm reconhecimento legal em seus países de origem. Aquele que solicita o refúgio em função de sua Orientação Sexual e/ou Identidade de Gênero é muitas vezes oriundo de países que não só não reconhecem a união homoafetivas como ilegalizam e punem com a morte a sexualidade distinta. A ameaça de morte por ser LGBTI é uma realidade em 4 dos principais países de origem para refugiados no mundo (ILGA, 2015, p.29). O parágrafo 69 do Relatório da Agência da ONU para Refugiados (ACNUR) sobre práticas discriminatórias contra indivíduos LGBTIs indica que a falta de um reconhecimento oficial pode resultar na discriminação por agentes privados, como agências de seguros e planos de saúde. Onde há reconhecimento do Casamento Homoafetivo, como no Brasil e alguns Estados membros da União Europeia, não existe distinção específica entre a união heterossexual ou homossexual. Por

\footnotetext{
${ }^{14}$ http://eur-lex.europa.eu/LexUriServ/LexUriServ.do?uri=OJ:L:2003:251:0012:0018:en:PDF acesso em 15/05/2016.
} 
interpretação, a união familiar nesse sentido deve endereçar os mesmos direitos aos cônjuges ou companheiros do mesmo sexo.

Sußner (2013) cita um caso $^{15}$ onde um solicitante Afegão matinha um relacionamento homoafetivo a mais de 6 meses, quando foi descoberto e atacado por um grupo de homens de sua vila. Nesse ataque, seu parceiro foi morto. Ao deixar o país, seu pedido de refúgio foi concedido na Áustria. Segundo o autor, conforme o estudo que fez da legislação austríaca, caso o parceiro do solicitante tivesse sobrevivido e solicitado a união familiar após o reconhecimento do refúgio do solicitante, este precisaria comprovar a união com o registro da mesma. Na lei Afegã, tal registro é inexistente (Sußner, 2013, p.180) e a ameaça de morte é uma realidade para indivíduos e casais homoafetivos.

A Reunificação familiar, no contexto regional Europeu, deve ser conforme a Convenção Europeia de Direitos Humanos. $\mathrm{O}$ artigo $8 \mathrm{em}$ especial, estabelece o direito do respeito à vida privada e à família. Nesse contexto, a Corte Europeia de Direitos Humanos em seus julgamentos busca balancear o princípio do controle dos Estados-membros sobre a imigração e o respeito aos Direitos Humanos (Sußner, 2013, p.183), estes são aqui elencados na forma da discussão da Reunificação Familiar.

Outro caso relevante para o tema da reunificação familiar, envolvendo o elemento do gênero é o caso Abdulaziz et al v. UK. Neste, três solicitantes legalmente residentes no Reino Unido entram com recurso contra o país frente à negação do seu pedido de reunificação familiar para que seus maridos pudessem residir no país juntamente com elas. O Governo negou o pedido segundo o argumento de proteção ao mercado de trabalho, alegando que homens estariam mais inclinados a adentrarem no mercado, o que não afetaria a reunificação familiar advindo do pedido de um homem residente no país para reunificação de uma esposa no exterior. O argumento para tal tratamento diferenciado entre as solicitações feitas por mulheres e solicitações feitas por homens foi rejeitado pela Corte Europeia de Direitos Humanos, sendo reconhecido que houve discriminação com base no gênero das solicitantes, estas mulheres (EU, 1985a).

O plano de fundo e os casos citados demonstram um cenário que possivelmente não favoreceria o reconhecimento da união familiar de solicitantes homoafetivos, levando em conta que no pedido do caso Abdulaziz et al V. UK, inicialmente negado pelo Reino Unido, havia clara demonstração e visibilidade da constituição de uma família, que nesse caso era heterossexual. Na argumentação das solicitantes, o Reino Unido deveria respeitar o direito de constituir uma família, o que pressupõe, segundo o parágrafo 62 do caso, a necessidade da existência de uma família (EC, 1985b).

Nesse ensejo é de grande consideração a visibilidade familiar como parte da fundamentação do pedido de reunificação. A marginalização LGBTI, incluindo o não reconhecimento legal citado anteriormente, atenta contrapontos necessários para proteção do Direito de reunificação. A vida familiar de pessoas separadas e refugiadas fica nesse sentido, tanto nos casos heterossexuais

\footnotetext{
${ }^{15}$ Mais informações sobre o caso (AsylGH 10.3.2010, C10 257854-0/2008/6E) disponível apenas em alemão no link: http://www.juridikum.at/fileadmin/user_upload/ausgaben/juridikum_4-2011.pdf
} 
quanto homossexuais, regulada por procedimentos legais restritivos que tornam a reunificação possivelmente inacessível, o que é agravado em casos LGBTI pelas razões já enumeradas. Sendo o provimento legal um dos pontos para reunificação, é considerável a maior dificuldade de reunificação familiar para famílias LGBTIs do que para famílias heterossexuais.

Em alguns países, como no já citado exemplo do Afeganistão, aqueles que mantêm algum tipo de relacionamento homoafetivo, o fazem de forma discreta. Mesmo o pertencimento a um social específico LGBTI não é explícito pelas razões de segurança e perseguição no país de origem. Evidentemente, esta forma de viver não exclui a perseguição existente e atenta contra a dignidade humana. Nesses casos, A invisibilidade familiar, considerando a necessidade da vida "discreta" em seu país de origem, dificultaria a reunificação familiar LGBTI já que além de não ser possível fornecer provimento legal da existência familiar, a própria visibilidade da vida familiar é afetada. Ou seja, em uma situação hipotética, dentro de um país cuja legislação criminalize ou não proteja LGBTIs, podemos considerar que mesmo que um casal homoafetivo conviva de facto em um relacionamento estável, recaindo assim na noção de vida familiar assim como um casal heterossexual, a prova de tal relacionamento viria com grande dificuldade considerando a inexistência social do mesmo, dada pela discrição necessária para segurança. Sem prova concreta da existência do laço familiar a possibilidade reunificação se tornaria remota.

Ocorre que os refugiados LGBTI normalmente passam pela Europa para aí sim serem direcionados a outros países como o Brasil. Desta forma, a análise das diretivas da União Europeia faz-se necessária.

Em casos de Refúgio pela Orientação Sexual e Identidade de Gênero, a possibilidade de prova para alegação de reunificação familiar é dificultada pelas mesmas razões que levam ao pedido de refúgio em si, logo é questionável prover um tratamento igual para avaliação de reunificação de refugiados heterossexuais quanto homossexuais, já que o tratamento igual dos últimos, em circunstâncias contextuais desiguais, caracterizaria a desigualdade no tratamento.

Na União Europeia, três diretivas são utilizadas na questão reunião familiar: a Free Movement Directive - Diretiva 2004/38/EC ${ }^{16}$, a Family Reunification Directive - Diretiva do Conselho 2003/86/EC ${ }^{17}$ e a Qualification Directive - Diretiva 2011/95/EU ${ }^{18}$, que juntas, definem o que é reunião familiar.

As pessoas LGBTI na condição de refugiada encontram diferentes problemas dependendo de onde o seu companheiro é - se da União Europeia (que é raríssimo na atual questão do deslocamento em massa de refugiados) ou se é proveniente de um terceiro país.

\footnotetext{
16 http://eur-lex.europa.eu/LexUriServ/LexUriServ.do?uri=OJ:L:2004:158:0077:0123:en:PDF acesso em 15/05/2016.

${ }^{17}$ http://eur-lex.europa.eu/LexUriServ/LexUriServ.do?uri=OJ:L:2003:251:0012:0018:en:PDF acesso em 15/05/2016

${ }^{18}$ http://eur-lex.europa.eu/LexUriServ/LexUriServ.do?uri=OJ:L:2011:337:0009:0026:de:PDF acesso em $15 / 05 / 2016$.
} 
Na Resolução ${ }^{19}$ de 24/05/2012 contra a homofobia na Europa, o Parlamento Europeu convocou a Comissão e os Membros da União Europeia para esclarecer que a Free Movement Directive não há qualquer tipo de discriminação baseada na orientação sexual ou identidade de gênero.

Como afirmado acima, o grande problema dos refugiados LGBTI é, além de provar a sua condição e motivo de fuga, é a da falta de documentação que comprove o vínculo do relacionamento. Como muitos refugiados que chegam no Brasil $^{20}$ vem de países em que há a criminalização das relações entre pessoas do mesmo ou mesmo não há a criminalização mas há a falta de segurança ao LGBTI, estes chegam a Europa sem qualquer prova de vínculo. Seus parceiros ou companheiros são separados à partir do momento em que eles cruzam a fronteira.

Em junho de 2010 no caso Schalk e Kolf v. Austria ${ }^{21}$ a Corte Europeia de Direitos Humanos reconheceu um casal LGBTI de fato como tendo "vida familiar, assim como os casais heterossexuais, onde afirma que "é artificial afirmar que, em contraste com casais de sexo oposto, os de mesmo sexo não podem gozar de vida familiar, de acordo com o art.8 da Convenção Europeia de Direitos Humanos". Confirmou este mesmo posicionamento em 2013, no caso X e outros v. Austria ${ }^{22}$ e no caso Vallianatos e outros v. Grécia ${ }^{23}$, reconhecendo que ao excluir o reconhecimento de casais do mesmo sexo e de exigir as uniões civis destes, a Grécia viola o art.14 da Convenção Europeia de Direitos Humanos que proíbe a discriminação, em conjunto com o art.8 (direito de respeitar a privacidade e a vida privada). A base deste caso foi a inexistência de coabitação do casal homoafetivo. Reconheceu a Corte que a coabitação não é mais um entrave para o reconhecimento da união homoafetiva. O mesmo aconteceu em um caso contra a Itália, o Oliari e outros v. Itália ${ }^{24}$.

A Corte ainda decidiu que mesmo nos casos em que os casais vivem juntos, mas não conseguem provar a duração desta coabitação, ou se há elementos financeiros ou mesmo dependência psicológica, há que considerar os laços familiares ${ }^{25}$.

Um país importantíssimo para a questão atual dos refugiados além da Turquia e Grécia, é o Chipre. Neste país, localizado entre ao largo das costas da Síria e Turquia, a Suprema Corte decidiu declinar ao pedido de reconhecer os casais do mesmo sexo, já que não reconhecem tal tipo de arranjo familiar. No atual panorama da União Europeia, os casais são separados e cada um fica em

\footnotetext{
${ }^{19}$ http://www.europarl.europa.eu/sides/getDoc.do?pubRef=-//EP//TEXT+TA+P7-TA-20120222+0+DOC+XML+V0//EN acesso em 15/05/2016.

${ }^{20}$ Nigéria, Senegal, República Democrática do Congo, Líbano, Guiné Bissau, Mali, Guiné Conacri, Angola, Afeganistão, Gana, Camarões, Paquistão, Egito, Iraque, Cuba, Colômbia, Bangladesh, Butão, Sudão, Sudão do Sul, Irã, Tunísia, Nepal, Burkina Faso, Serra Leoa, Gambia, Somália, Togo, Eritreia, Quênia, Sri Lanka, de acordo com a pesquisa COI, do LARI/ Universidade Católica de Santos/ACNUR-ONU.

${ }^{21} \mathrm{http}$ ://hudoc.echr.coe.int/app/conversion/pdf/?library=ECHR\&id=001-99605\&filename=00199605.pdf\&TID=ybkaxcidrc acesso em 15/05/2016

${ }^{22}$ http://echrblog.blogspot.com.br/2013/02/x-v-austria-judgment.html acesso em 15/05/2016

${ }^{23} \mathrm{http}: / /$ echrblog.blogspot.com.br/2013/11/vallianatos-judgment-on-sexual.html acesso em 15/05/2016

${ }^{24}$ http://hudoc.echr.coe.int/eng?i=001-

156265\&sa=X\&ved=0CDUQ9QEwD2oVChMIwICr1bn2xgIVI75yCh186Qh- acesso em 15/05/2016

${ }^{25}$ Casos Quintana Zapata v. Espanha e Emonet e outros v. Suiça.
} 
um país ${ }^{26}$. Na Itália, nas Cortes de Reggio Emilia e Pescara ${ }^{27}$ reconheceu que os casais do mesmo sexo que se casem no exterior sejam reconhecidos como tais dentro do território italiano.

O verdadeiro drama ocorre quando estes casais homoafetivos são separados e cada um vai para um país ou acampamento de refugiados. Quando não há possibilidade de reconhecimento de união entre pessoas do mesmo sexo no país de origem, os casais escolhem a união estável, ou seja, a união de fato. De acordo com o art.3 (2) do Free Movement Directive da União Europeia, o país de acolhida deverá facilitar a entrada e a residência do parceiro. Infelizmente, isto não acontece, como no caso de Luxemburgo, onde a lei de imigração interna não reconhece as uniões que não foram registradas (casamento civil ou união civil), desconsiderando as uniões de fato ${ }^{28}$.

Mas há decisões históricas como as do Tribunal de Grosselo, na Itália, que fez uma campanha pública com todos os prefeitos das cidades da região, para que fizessem as transcrições de casamento entre pessoas do mesmo sexo que vieram do exterior na condição de refugiadas. Tal iniciativa foi apoiada pela ONG LGBT Avvocatura a per i diritti LGBT ${ }^{29}$.

A reunificação de famílias, no tocante à questão dos refugiados LGBTI, tem como base o respeito aos direitos fundamentais da vida privada e vida familiar, assim como o da nãodiscriminação. Há outra dificuldade na reunião familiar LGBTI, assim como em casais heterossexuais: os refugiados têm que provar que recebem salário suficiente para pagar pelos seus gastos e de sua família. Em alguns países, o pedido de reunião familiar tem que ocorrer até três meses depois do reconhecimento do pedido de refúgio.

A agência da ONU para refugiados, ACNUR, verificou que não é ponderado o período curto de somente três meses para tal pedido, já que poderá durar alguns meses até encontrar os membros da família e muitos mais meses para separar a documentação necessária que é extremamente burocrática.

Muitas pessoas acabam sofrendo com a separação de sua família, podendo demorar até sete anos o processo de reunificação familiar. A ausência de um familiar aumenta a sua vulnerabilidade que de acordo com o ACNUR, é muito maior em refugiados LGBTI, já que sua própria condição de orientação sexual ou de identidade de gênero é vulnerável.

O processo de reunião familiar pode demorar até 7 anos, de acordo com a Cruz Vermelha ${ }^{30}$, já que a burocracia dos países que estão recebendo estes refugiados, exige uma série de documentos que estes em sua fuga, deixaram para trás.

Os entraves de alguns países da Europa, principalmente os que são porta de entrada da atual crise dos refugiados, tem uma interpretação do seja família, considerando somente a família nuclear - esposa ou marido, filhos menores e ainda parentes desacompanhados de menores, ignorando completamente os dramas da guerra civil e da perseguição, que acabam compondo novos arranjos

\footnotetext{
${ }^{26}$ http://www.cylaw.org/cgi-bin/open.pl?file=apofaseis/aad/meros_4/2010/4-201007-1582-

08.htm\&qstring=1582 acessso em 15/05/2016

${ }^{27}$ http://www.articolo29.it/wp-content/uploads/2012/11/nota-ministero-interini-5-11-2012.pdf acesso em $15 / 05 / 2016$

${ }^{28}$ http://www.ehp.lu/uploads/media/Corporate_Immigration_Luxembourg.pdf acesso em 15/05/2016

${ }^{29} \mathrm{http}: / /$ www.articolo29.it/wp-content/uploads/2014/04/ordinanza-tribunale-di-Grosseto-3-aprile-20141.pdf acesso em 15/05/2016.

${ }^{30} \mathrm{http}: / /$ eur-lex.europa.eu/legal-content/en/TXT/?uri=celex:32003L0086 acesso em 15/05/2016.
} 
familiares, como as famílias extensas. A reunificação familiar é o caminho necessário para fazer a vida em família possível, ajudando a criar estabilidade sociocultural e facilitando a integração dos refugiados, colaborando com a coesão, direito fundamental descrito na Convenção Europeia de Direitos Humanos.

O direito de família e a reunião familiar na questão dos refugiados LGBTI são ainda pouco discutidos. Apesar das poucas garantias, os LGBTI continuam fugindo de seus países de origem com seus amores e vivem um novo drama ao chegarem na Europa e depois, na integração. A família dos refugiados LGBTI tem que ser reconhecida para que finalmente eles possam estar em paz e reconstruir sua vida.

\section{REFERÊNCIAS}

BRAIMAH, Tim Sahliu. Same-Sex Oriented Persons as Member of a Particular Social Group: what's non discrimination got to do with it? International Journal of legal research, vol.2, 2016.

CARROLL, Aengus; ITABORAHY, Lucas P. STATE-SPONSORED HOMOPHOBIA. International Lesbian, Gay, Bisexual, Trans and Intersex Association (ILGA). Geneva, 2015.Disponível em: <http://old.ilga.org/Statehomophobia/ILGA_State_Sponsored_Homophobia_2015.pdf>.Acesso em 07 abr. 2016

COUNCIL OF EUROPE. European Court of Human Rights. European Convention on Human Rights. Rome. 1950. Disponível em: <http://www.echr.coe.int/Documents/Convention_ENG.pdf> Acesso em: 05 Jun 2016

COUNCIL OF EUROPE. European Court of Human Rights. Abdulaziz, Cabales, and Balkandali v UK (Application nos. 9214/80; 9473/81; 9474/81). (Online). 1985. Disponível em: http://www.equalrightstrust.org/ertdocumentbank/Microsoft\%20Word\%20-

\%20Case\%20of\%20Abdulaziz\%20Cabales\%20\%20Balkandali\%20v\%20UK.pdf> Acesso em: 05 Jun 2016

COUNCIL OF EUROPE. European Court of Human Rights. Abdulaziz, Cabales, and Balkandali v UK (Application nos. 9214/80; 9473/81; 9474/81). Strasbourg. 1985b. Disponível em:

<http://hudoc.echr.coe.int/eng\#\{"dmdocnumber":["695293"],"itemid":["001-57416"]\}> Acesso em: 05 Jun 2016

EUROPEAN UNION AGENCY FOR FUNDAMENTAL RIGHTS. Protection Against Discrimination on the Grounds of Sexual Orientation, Gender Identity and Sex Characteristics in the EU, 2015.

JANSEN, Sabine. Fleeing Homophobia. Refworld, 2011.

SUßNER, Petra. Invisible Intersections, queer interventions: Same sex family reunification under the rule of asylum law. In: Fleeing Homophobia. New York: Routledge, 2013. p. 176-188.

UNHCR. Guidelines on International Protection No. 9: Claims to Refugee Status based on Sexual Orientation and/or Gender Identity within the context of Article 1A(2) of the 1951 Convention and/or its 1967 Protocol relating to the Status of Refugees

<http://www.refworld.org/docid/50348afc2.html> acesso em 15/05/2016.

Gender Identitites, 2015.

Protecting Persons with Diverse Sexual Orientations and

ZOMORODI, Gitta. Responding to LGBT forced migration in East Africa. FMR, 2016.

Revista do Direito [ISSN 1982-9957]. Santa Cruz do Sul, v. 3, n. 50, p. 71-80, set./dez. 2016. https://online.unisc.br/seer/index.php/direito/index 
COMO CITAR ESSE DOCUMENTO:

GORISCH, Patricia Cristina Vasques de Souza. A família LGBTI na perspectiva do direito internacional dos refugiados. Revista do Direito, Santa Cruz do Sul, v. 3, n. 50, p. 71-80, set. 2016. ISSN 19829957. Disponível em: <https://online.unisc.br/seer/index.php/direito/article/view/8563>. Acesso em: doi:http://dx.doi.org/10.17058/rdunisc.v3i50.8563. 